\title{
Los museos como espacios de reflexión crítica para la recuperación del patrimonio cultural de la nación del centro histórico de Lima
}

\author{
Museums as spaces of critical reflection for the recovery of national \\ cultural heritage of the Historic Center of Lima
}

Ana María Lebrún Aspíllaga ${ }^{1}$

\section{RESUMEN}

El presente artículo tiene como objetivo analizar si los museos pueden ser espacios de reflexión crítica para la recuperación del Patrimonio Cultural de la Nación del Centro Histórico de Lima, a partir de las exposiciones temporales y la oferta educativa en los museos. Los museos, en la actualidad, cumplen una misión relevante, debido a que son espacios de educación continua y reflexión crítica, a través de las exposiciones permanentes $y$ temporales que generan identidad.

La investigación es de tipo cuantitativo - no experimental, con un enfoque descriptivo - transversal. La unidad de medida son seis museos del Centro Histórico de Lima, los mismos que han sido seleccionados bajo tres criterios: valor patrimonial de la UNESCO; condiciones de infraestructura y función, y espacio de reflexión.

Los resultados obtenidos determinan que los museos cuentan con la infraestructura necesaria para que cumplan sus funciones de museo al ser espacios abiertos al público, cuentan con exposiciones permanentes y temporales, dispone de personal profesional y técnico especializado, tiene un presupuesto anual, es una institución sin fines de lucro y presenta una oferta educativa para los visitantes. Asimismo, los guiones museográficos de la exposición permanente permiten la reflexión crítica, orientan al visitante a adquirir nuevos conocimientos; la exposición contribuye al desarrollo cultural y al reforzamiento de la identidad de la población limeña, concluyendo que las exposiciones logran generar conciencia y sensibilización en los visitantes, como un hilo conductor para reforzar y apoyar los conocimientos previos, permitiendo el desarrollo sostenible de la ciudad para la preservación y conservación del Patrimonio Cultural de la Nación para las generaciones futuras, como una pieza clave para la construcción del presente, permitiendo el diálogo intercultural y la creatividad cultural, mediante la interpretación y el respeto de la comunidad local para su transformación.

\section{Palabras clave}

Centro Histórico de Lima; museos del Centro Histórico de Lima; Patrimonio Cultural de la Nación; recuperación del Patrimonio Cultural; reflexión crítica

\section{ABSTRACT}

The purpose of this article is to analyze if museums can be spaces of critical reflection for the recovery of the National Cultural Heritage of the Historic Center of Lima through temporary exhibitions and educational offers in museums. Currently, museums fulfill an important mission since they are spaces for continuous education and critical reflection thanks to permanent and temporary exhibitions that create identity.

\footnotetext{
Arquitecta. Magíster en Museología. Directora de la carrera de Arquitectura y Diseño de Interiores de la Universidad Privada del Norte - sede Comas. Past Directora de Museos y Gestión del Patrimonio Histórico del Instituto Nacional de Cultura y del Museo Postal y Filatélico del Perú. Gerente General de RUTA 4 SAC Planificación y Acción Cultural. Vicepresidenta y Directora de Proyectos Nacionales e Internacionales de Instituto RUTA 4 Investigación y Proyectos.
} 
This is a quantitative non-experimental research with a descriptive-transversal approach. The unit of measurement is six museums in the Historic center of Lima, which have been chosen using the following criteria: UNESCO heritage value, infrastructure and operating conditions, and space for reflection.

The results obtained have determined that museums have adequate infrastructure for the fulfillment of their functions, as they are open to the public, have permanent and temporary exhibitions, count on specialized professional and technical personnel, work with annual budgets, are nonprofit institutions, and provide educational offers for visitors.

Likewise, the museum scripts of permanent exhibitions allow critical reflection, guide visitors to acquire new knowledge and contribute to cultural development and the reinforcement of the identity of Lima's population. Thus, it may be concluded that the exhibitions succeed in generating awareness and sensitization of visitors as a guiding thread to reinforce and support previous knowledge. This allows the sustainable development of the city for the preservation and conservation of the Cultural Heritage of the Nation for future generations, which is key to the construction of the present, as it enables intercultural dialogue and cultural creativity, through interpretation and respect of the local community for its transformation.

\section{Keywords}

Historic Center of Lima, museums in the Historic Center of Lima, National Cultural Heritage, Cultural Heritage recovery, critical reflection.

\section{INTRODUCCIÓN}

Lima, capital del Perú, la tres veces coronada Villa, se sitúa en el valle de Pachacámac, el cual es atravesado por el río Rímac; fue fundada el 18 de enero de 1535. La traza inicial de la ciudad estaba constituida por 117 manzanas formando un rectángulo de 9 por 13 manzanas. Cada una de ellas formaba un cuadrado perfecto de 450 pies de lado y estaba dividido en 4 solares, las calles medían 40 pies de ancho, las nuevas casas y solares se construían sobre huacas y caminos antiguos (Günther, 2012).

El Centro Histórico de Lima fue inscrito el 13 de diciembre de 1991 por el Comité del Patrimonio Mundial de la Convención sobre la protección del Patrimonio Mundial, Cultural y Natural de la UNESCO, como Patrimonio Cultural de la Humanidad, bajo el criterio (iv), debido a que es un ejemplo eminentemente representativo de un tipo de construcción o de conjunto arquitectónico o tecnológico, o de paisaje que ilustre uno o varios periodos significativos de la historia humana" (United Nations Educational, Scientific and Cultural Organization, Intergovernmental Committee for the Protection of the World Cultural and Natural Heritage, World Heritage Centre, 2015, p. 55).

En la actualidad, el Centro Histórico de Lima ocupa áreas jurisdiccionales de los distritos del Cercado de Lima, Rímac y periféricamente pequeñas áreas de los distritos de San Juan de Lurigancho, El Agustino, La Victoria, Jesús María, Breña y San Martín de Porras.

El artículo 25 de la Ordenanza $\mathrm{N}^{\circ}$ 201: Plan Maestro Centro de Lima, del 12 de abril de 1999 (Municipalidad Metropolitana de Lima [MML], 1999) define al Centro Histórico de Lima como "una estructura socioeconómica, espacial y cultural, que da testimonio de un período significativo de la historia de la ciudad, constituye expresión de la creatividad cultural de la comunidad local y mantiene las características y calidades de vida propias de núcleos urbanos en actividad".

El Centro Histórico de Lima enfrenta una serie de problemas de carácter socioeconómico, medioambiental y cultural basado en una 
permanente carencia de cultura cívica, que se ve reflejada en el reducido progreso del suelo urbano y el espacio público, a pesar del valor artístico, arquitectónico, histórico y patrimonial que posee.

En relación a la problemática relacionada al ámbito socioeconómico en el Centro Histórico de Lima, la vivienda constituye uno de los principales problemas, esta área es residencia de habitantes con escasos recursos económicos, migrantes, personas de la tercera edad, entre otros.

En el estudio realizado por el Centro de Investigación Documentación y Asesoría Poblacional (CIDAP, s.f.), el Centro Histórico de Lima alberga más de 1000 inmuebles con valor monumental, de los cuales 555 son inmuebles civiles y domésticos y 53 son monumentos religiosos que se encuentran en riesgo de colapso. Según la empresa APOYO S.A., hasta enero de 2006 existían 47,184 viviendas en el Centro Histórico de Lima, ubicadas en 672 monumentos y 63 ambientes urbanos residenciales. Igualmente, el Instituto Nacional de Defensa Civil - INDECI señala que 17,432 inmuebles se encuentran en alto riesgo de colapso (con una antigüedad de entre 100 y 150 años), habitados aproximadamente por 50,000 personas. Dentro del Centro Histórico de Lima existen más de 100 edificaciones desocupadas (1'500,000 m2 edificados).

De acuerdo con ellevantamiento de información realizado por la Municipalidad Metropolitana de Lima (MML, 2014), el Centro Histórico de Lima tiene problemas relacionados con la proliferación de imprentas en casas, casonas históricas, galerías y locales que no cuentan con medidas de seguridad, perjudicando de esta manera la calidad de vida de los habitantes que viven en el entorno de estos locales. En lo que respecta a la seguridad ciudadana, la inseguridad y violencia es notable, la misma que se ve reflejada en la depredación del Patrimonio Cultural de la Nación y diversos delitos como el robo, violencia familiar, hurto y lesiones que generan violencia social.

Considerando el ámbito medioambiental, el principal problema del Centro Histórico de Lima se relaciona con los vehículos de transporte público y privado que transitan por sus avenidas, calles y jirones, los que generan contaminación del aire, los mismos que tienen muchos años de antigüedad. Según la Municipalidad Metropolitana de Lima, el uso de combustible contaminante genera material particulado y gases de combustión que alteran las características del aire. Asimismo, otra fuente de contaminación del aire son las fuentes de emisiones comerciales como las pollerías, restaurantes y panaderías.

La contaminación visual es otro de los problemas que se observa en el Centro Histórico de Lima, principalmente con la ubicación de letreros y avisos publicitarios, pintas y afiches de colores destellantes que generan ruido visual y agreden al ambiente urbano, señales de tránsito y anuncios mal ubicados, cables expuestos, así como edificios deteriorados y sin mantenimiento permanente que influyen en la degradación constante del entorno.

La creación de los paraderos y estaciones del Metropolitano ha generado un efecto negativo que perjudica considerablemente el perfil urbano del Centro Histórico de Lima. A esto se agrega la carencia de estudios sobre movilidad y transporte vehicular y ciclovías, así como un inventario del parque automotor y los estacionamientos para vehículos y bicicletas existentes.

La contaminación sonora tiene un alto índice, debido a la permanente carga vehicular de transporte público y privado en las avenidas, calles y jirones del Centro Histórico de Lima, llegando a "niveles superiores a los 80 decibeles, siendo el estándar recomendado por la Organización Mundial de la Salud de 55 decibeles" (Municipalidad Metropolitana de Lima, 2014, p. 85). Otra fuente que incrementa la contaminación acústica son los "establecimientos comerciales que representan fuentes fijas generadoras de ruido tales como bares, cantinas, restaurantes, imprentas, casinos, tiendas de venta de ropa y electrodomésticos, venta ambulatoria de Cds y DvDs, etc." (Municipalidad Metropolitana de Lima, 2014, p. 85). Las fuentes fijas generan "niveles entre 72 y 75 decibeles durante el día, superando así el estándar de calidad ambiental permitido para zonas comerciales el cual es de 
70 decibeles". (Municipalidad Metropolitana de Lima, 2014, p. 86).

Los residuos sólidos domiciliarios que se han generado en el Centro Histórico de Lima en el año 2013 alcanzan 99,12 toneladas diarias, para ello se tiene como base el censo poblacional del INEI - 2007 realizado por la
Municipalidad Metropolitana de Lima (2014, p. 86). Permanentemente se observa residuos en vías públicas propiciadas por las actividades comerciales y de servicios, así como de los edificios y quintas que no respetan los horarios de recolección, generando desorden, falta de limpieza y acumulación de residuos (Municipalidad Metropolitana de Lima, 2014).

Tabla 1.

Generación de residuos sólidos en el Centro Histórico de Lima.

\begin{tabular}{|c|c|c|c|c|c|c|}
\hline Distrito & Porcentaje & $\begin{array}{c}\text { Poblacional } \\
\mathbf{2 0 0 7}\end{array}$ & $\begin{array}{c}\text { Población } \\
\text { al 2013 }\end{array}$ & $\begin{array}{c}\text { GPC } \\
\text { (kg./hab./día) }\end{array}$ & $\begin{array}{c}\text { Generación } \\
\text { total diaria } \\
\text { (Kg./día) }\end{array}$ & $\begin{array}{c}\text { Generación } \\
\text { total diaria } \\
\text { (Ton.) }\end{array}$ \\
\hline $\begin{array}{c}\text { Cercado de } \\
\text { Lima* }\end{array}$ & $67 \%$ & 97,907 & 91,021 & 0.69 & 62804.49 & 62.80 \\
\hline Rimac** & $32 \%$ & 46,762 & 52,352 & 0.67 & 35075.94 & 35.08 \\
\hline Otros & $1 \%$ & 1,461 & 1,461 & 0.85 & 1242.11 & 1.24 \\
\hline Total & $100 \%$ & 146,126 & 144,834 & 0.74 & 99122.53 & 99.12 \\
\hline
\end{tabular}

Fuente: Municipalidad Metropolitana de Lima, 2014, p. 87.

(*) Tasa de crecimiento para el Cercado de Lima: anual de $-1.07 \%$ (decreciente).

(**) Tasa de crecimiento para el Rímac: anual $1.9 \%$ (creciente).

En el Centro Histórico de Lima, se ha podido detectar, dentro de los segmentos poblacionales que conviven en la zona de influencia a los vecinos (habitantes), comerciantes y población flotante, los que contribuyen a la generación o mantenimiento de puntos críticos.

De acuerdo con el estudio realizado por la Municipalidad Metropolitana de Lima (2014, p.88):

- Existen inadecuadas prácticas ambientales, es decir, arrojan sus residuos en la vía pública, hacen un mal uso o dañan los contenedores y/o papeleras colocadas en sus zonas, sacan las bolsas de basura fuera del horario de recolección, además de ubicarlas donde no corresponde y embolsarlas inadecuadamente.

- Se acepta el desorden y la suciedad como parte del status quo de la ciudad, se critica la presencia de basura en las calles y se supone que la presencia de basura es una situación "normal" en su comunidad.

- Hay poca iniciativa para generar cambios en los estilos de vida de los vecinos que residen en sus barrios, quintas o solares $\mathrm{y} / \mathrm{o}$ para realizar una crítica al transeúnte que arroja su basura a la calle, y evitan hacerlo por temor o vergüenza.

- Perciben una ausencia en la aplicación de sanciones relacionadas con este tema, sumada a la falta de información sobre cómo realizar un manejo adecuado de sus residuos sólidos.

- En el caso de quienes visitan o transitan por el Centro Histórico de Lima, se añade otro factor: la falta del sentido de pertenencia con esta parte de la ciudad.

El Centro Histórico de Lima carece de itinerarios o rutas peatonales en zonas de interés, de mobiliario urbano, servicios higiénicos de calidad y en cantidad suficiente, de señalización adecuada y accesibilidad para todos.

El Centro Histórico de Lima, con relación al ámbito cultural, ha contado con diversos intentos para la conservación de su patrimonio histórico, los que han fracasado, principalmente por la falta de continuidad y concertación con la población, esto debido 
a la falta de reglamentos específicos para generar continuidad, siendo de necesidad una fiscalización constante y permanente.

El habitante del Centro Histórico de Lima es multicultural, y su patrimonio construido es multitemporal: a diferentes edificios corresponden diferentes técnicas, estados de conservación y materiales, y, por tanto, son necesarios lineamientos específicos, que hoy no existen y que deben crearse.

Se carece de programas de mantenimiento para los edificios patrimoniales y de contexto, así como de protocolos preventivos y de respuesta para los bienes culturales frente a desastres naturales y accidentales como incendios, inundaciones, entre otros. Igualmente, no se cuenta con ordenanzas que apoyen iniciativas de los vecinos en programas culturales, de preservación y de conservación del patrimonio cultural inmueble.

El Centro Histórico de Lima carece de un plan integral de capacitación de ciudadanía, identidad, conciencia y sensibilización social; no se interrelaciona con el sector empresarial $e$ institucional para el apoyo al vecino en actividades culturales, ni el involucramiento con los jóvenes para la generación de bolsas de trabajo.

No existe un empoderamiento de los sectores como: colegios profesionales, universidades, asociaciones vecinales, asociaciones no gubernamentales, sociedad civil, comunidades extranjeras, quienes intervengan directamente en el fortalecimiento de la identidad, en la educación y difusión de los valores del patrimonio monumental de Lima.

Asimismo, no se desarrollan proyectos de investigación de los monumentos arquitectónicos del Centro Histórico de Lima, trabajos científicos y aportes académicos, lo que se ve reflejado en el poco conocimiento de los vecinos del Centro Histórico de Lima en relación con el patrimonio inmueble que se encuentra en toda la zona monumental.

El análisis que realizan González, Gil y Vilches (2002) sobre el papel que juegan los museos en la educación ciudadana a través de las exposiciones, contribuye a transmitir distintas visiones para favorecer la reflexión sobre los problemas que afectan a la humanidad en cuanto a la ciencia, tecnología, sociedad, ambiente, entre otros.

A través del tiempo, la sociedad peruana, no cuenta con políticas, planes, programas ni proyectos integrales que promuevan un proceso de institucionalización de una entidad coordinadora de los sectores públicos, la sociedad civil y el sector privado que invierta en las mejoras el Centro Histórico de Lima; para esto es preciso considerar que los museos pueden ser espacios de reflexión crítica para la recuperación del Patrimonio Cultural de la Nación del Centro Histórico de Lima, teniendo en cuenta a la población residente y flotante que circula diariamente por el Centro Histórico de Lima. Para ello, el objetivo de la presente investigación es analizar que los museos sean espacios de reflexión crítica para la recuperación del Patrimonio Cultural de la Nación del Centro Histórico de Lima, a partir de las exposiciones temporales y la oferta educativa en los museos, con un programa integral de sensibilización y concientización para el cambio de costumbres de la población en general.

Es imperativo contar con un plan de manejo del Centro Histórico de Lima que integre recursos que hagan sostenible la habitabilidad, movilidad y vida cotidiana de la población en general, convirtiéndose en un espacio de difusión cultural que permita convertirlo en un centro histórico vivo.

La importancia de conservary restaurar radica no solo en rescatar el legado arquitectónico declarado como patrimonio, sino también se trata del rescate de escenarios que permiten viajar en el tiempo, recreando y viviendo la historia.

El rescate, revalorización y restauración de las edificaciones patrimoniales que forman parte de la memoria e imagen urbana del Centro Histórico de Lima y, a la vez, que cuenten con un valor singular y de identidad del lugar no solo se convierten en instrumentos para recuperar el legado cultural sino también 
tiene como potencialidad generar recursos económicos que reviertan en el crecimiento y desarrollo de los pueblos convirtiéndose de esta manera en inversiones sostenibles, deteniendo el proceso de deterioro del Centro Histórico de Lima.

El Patrimonio Cultural de la Nación que perdura en el Centro Histórico de Lima, constituye una pieza clave para la construcción del presente, generando desarrollo sostenible con los diversos actores sociales que habitan y hacen uso de él, para consolidar su recuperación y transformación.

Los actores sociales del Centro Histórico de Lima se encuentran conformados por las instituciones públicas, privadas, organizaciones sin fines de lucro y organizaciones de la sociedad civil. Los actores gubernamentales son: Gobierno Regional de Lima, Ministerio de Vivienda, Construcción y Saneamiento, Ministerio de Cultura, Ministerio de Educación, Municipalidad Metropolitana de Lima, municipalidades distritales, comisarias, museos, galerías, organismos públicos descentralizados. Dentro de los actores privados, se encuentran los bancos, financieras, empresarios y los medios de comunicación. En el grupo de las organizaciones sin fines de lucro, se encuentran las iglesias, fundaciones y organismos no gubernamentales; finalmente, dentro de la sociedad civil se encuentran las diversas asociaciones, organizaciones, comités, juntas vecinales, comedores populares y comedores del vaso de leche.
Los beneficiarios directos $e$ indirectos con la recuperación del Patrimonio Cultural de la Nación, el espacio público y el suelo urbano del Centro Histórico de Lima son los siguientes:

- Residentes permanentes (habitantes y comerciantes) y población flotante.

- Turistas nacionales y extranjeros.

- Empresarios constituidos por aquellos que brindan servicios turísticos: hoteles, hospedajes, albergues, restaurantes, comerciantes, entre otros.

- La población en general, a través de las actividades económicas generadas en torno al movimiento turístico.

- Los habitantes de la región y localidades cercanas mediante la generación de mayor oferta turística.

La Carta de Washington, 1987, (Consejo Internacional de Monumentos y Sitios Históricos, ICOMOS, 1987), la Carta Internacional para la Conservación y Restauración de los Monumentos y los Sitios Históricos - Venecia, 1964 (ICOMOS, 1964) y la Declaración de Nairobi, 1976 (Organización de las Naciones Unidas para la Educación, la Ciencia y la Cultura, UNESCO, 1976) inciden en la importancia de las ciudades históricas; conservar la calidad de las poblaciones y áreas urbanas históricas y favorecer la armonía entre la vida individual y colectiva; la preservación, protección, conservación y restauración para la salvaguarda de los conjuntos históricos y la conservación de la calidad de las poblaciones y áreas urbanas como parte de la memoria de la humanidad, respectivamente.

En la actualidad los museos cumplen una 


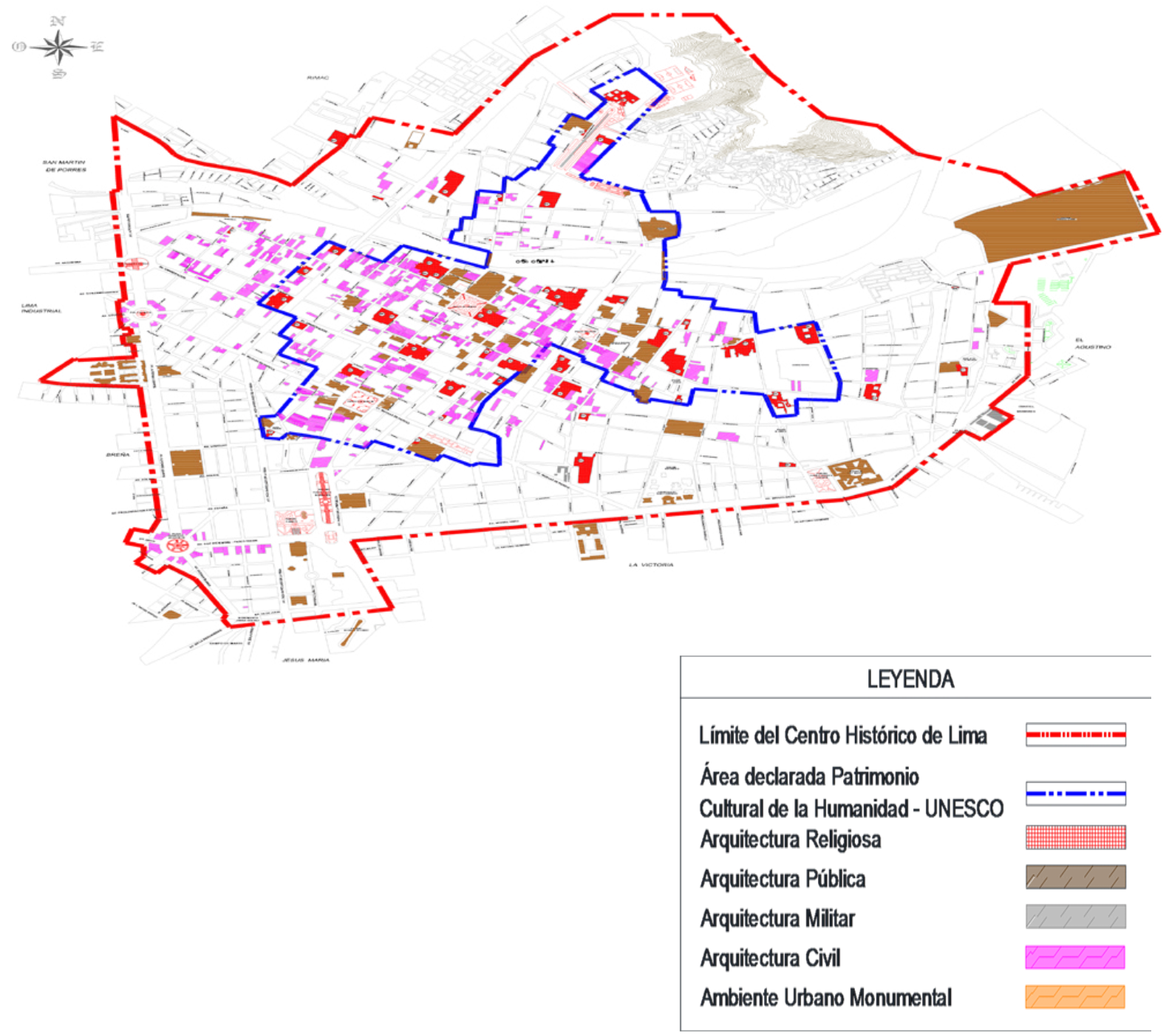

Figura 1. Plano de ubicación de los monumentos ubicados en el Centro Histórico de Lima.

Fuente: Ministerio de Cultura, 2010 
misión relevante en la sociedad actual; de acuerdo con los estatutos del Consejo Internacional de Museos - ICOM2 (2017, p. 3), se define al museo como

una institución permanente sin fines de lucro al servicio de la sociedad y de su desarrollo, abierta al público, que adquiere, conserva, investiga, transmite $y$ expone el patrimonio tangible $e$ intangible de la humanidad y de su entorno para la educación, el estudio y el deleite.

Asimismo, la $22^{\circ}$ Asamblea General en Viena (Austria) del 24 de agosto de 2007 (ICOM, 2007) promueve la protección del patrimonio natural y cultural, material e inmaterial, mueble e inmueble, sin limitaciones de fronteras nacionales o intereses particulares, así como el respeto de la diversidad cultural de los pueblos.

En la actualidad, el concepto de MUSEO es un término que varía según cambia la sociedad, y la nuestra lo hace a una velocidad vertiginosa, en especial a partir del uso de Internet. El museo es un centro dinámico, interactivo, donde la gente pueda compartir y contrastar información acorde a las nuevas generaciones que precisan nuevos espacios de comunicación.

Las nuevas tecnologías están marcando una nueva forma de pensar, de actuar, de aprender y de enseñar. El museo es un espacio para todos, no solo para eruditos, incluso para las personas con discapacidades que antes tenían muy limitada su visita al museo $y$, a partir de las TIC, el visitante ya no es solamente un espectador.

Los museos cumplen también la función esencial de acercar al público a sus instalaciones, para ello es necesario crear estrategias permanentes para:

- Encuentro con el Patrimonio Cultural de la Nación.

- Espacio de interrelación e interacción.

- Reflexión sobre la identidad.

- Recrear mundos virtuales en torno a los museos.

- Utilización de las TIC.

Teniendo en cuenta el párrafo que antecede, un museo no es solamente un contenedor $y$ un contenido (infraestructura y colección), es un espacio ideal para el aprendizaje, un lugar de descubrimiento, conocimiento y espacio de reflexión crítica.

La relación entre educación, cultura y museos se encuentra asociada principalmente al estudio de los procesos de socialización formales, no formales e informales (escuelas, universidades, familia, medios de comunicación y religiones), los que conforman la totalidad del sistema educativo.

2 El Consejo internacional de museos (ICOM) es la única organización que representa a los museos y sus profesionales. Desde 1946, el ICOM acompaña a los actores de la comunidad museística en su misión de preservar, conservar y transmitir los bienes culturales. El Consejo internacional de museos se rodea de colaboradores institucionales para cumplir sus objetivos.

El ICOM se caracteriza por una gobernanza mundial jerarquizada e inclusiva. Reúne más de 35.000 miembros y se organiza en Comités nacionales que representan a 136 países y territorios y en Comités internacionales compuestos de expertos en distintas especialidades museísticas.

La sede de la Secretaría general del ICOM se sitúa en la Casa de la UNESCO en París (Francia). 




Figura 2. Plano de ubicación de los museos del Centro Histórico de Lima. Fuente: Ministerio de Cultura, 2010, elaborado por Fabiola Castillo C. 
Tabla 2 .

Relación de museos ubicados en el Centro Histórico de Lima.

\begin{tabular}{|c|c|c|c|}
\hline Tipo & Numeración & Nombre del Museo & Dirección \\
\hline \multirow{7}{*}{$\begin{array}{l}\text { Museos } \\
\text { arqueológicos, } \\
\text { antropológicos y } \\
\text { etnográficos }\end{array}$} & 1 & $\begin{array}{l}\text { Museo de Arqueología y Antropodología de la Universidad } \\
\text { Nacional Federico Villarreal }\end{array}$ & Jiron Cañete 597 - Lima \\
\hline & 2 & Museo de Arqueología Josefina Ramos de Cox & Jiron Rufino Torrico 1164 - Lima \\
\hline & 3 & $\begin{array}{l}\text { Museo de Arqueología y Antropodología de la Universidad } \\
\text { Nacional Mayor de San Marcos }\end{array}$ & Avenida Nicolás de Piérola 1222 - Lima \\
\hline & 4 & Museo de Artes y Tradiciones Populares & Jiron de la Unión 554 - Lima \\
\hline & 5 & $\begin{array}{l}\text { Museo de Etnográfico Amazónico del Centro Cultural } \\
\text { José Pio Aza }\end{array}$ & Jirón Callao 562 - Lima \\
\hline & 6 & Museo Nacional de la Cultura Peruana & Avenida Alfonso Ugarte 650 - Lima \\
\hline & 7 & Musco Nacional Afroperuano & Jiron Ancash 536 - Lima \\
\hline \multirow{5}{*}{ Museos de Arte } & 8 & Museo de Arte de Lima (MALL) & Parque de la Exposición, Paseo Colon 125 - Lima \\
\hline & 9 & Museo Arte Italiano & Avenida Paseo de la República 250 - Lima \\
\hline & 10 & $\begin{array}{l}\text { Museo de Arte de la Universidad Nacional Mayor de } \\
\text { San Marcos }\end{array}$ & Avenida Nicolás de Piérola 1222 - Lima \\
\hline & 11 & Museo del Banco de Reserva del Perú & Jiron Ucayali 271 - Lima \\
\hline & 12 & Pinacoteca Municipal Ignacio Merino & Pasaje Santa Rosa 116 - Lima \\
\hline \multirow{2}{*}{$\begin{array}{l}\text { Museos de Ciencia } \\
\text { y Tecnología }\end{array}$} & 13 & Museo del Cerebro & Jirón Ancash 1271 - Lima \\
\hline & 14 & Museo Andrés del Castillo & Jirón de la Unión 1030 - Lima \\
\hline \multirow{12}{*}{ Museos de Historias } & 15 & Museo de los Combatientes del Morro de Arica & Jirón Calloma 125 - Lima \\
\hline & 16 & Museo de la Identificación (RENIEC) & $\begin{array}{l}\text { Torre II, Piso 2, Torre Centro Cívico, Avenida } \\
\text { Bolivia } 109 \text { - Lima }\end{array}$ \\
\hline & 17 & Museo de Historia Policial & Jirón Huanta 706, Plaza Italia, Barrios Altos - Lima \\
\hline & 18 & Museo Electoral y de la Democracia (JNE) & Avenida Nicolás de Piérola 1070 - Lima \\
\hline & 19 & Panteón de los Próceres & Avenida Nicolás de Piérola 1220 - Lima \\
\hline & 20 & Museo Taurino de la Plaza de Acho & Jirón Hualgayoc 332 - Lima \\
\hline & 21 & Museo Gráfico El Peruano & Jirón Quilca 556 - Lima \\
\hline & 22 & Museo del Congreso y de la Inquisición & Plaza Bolívar, Jirón Junín 548 - Lima \\
\hline & 23 & Museo de la Compañia de Bomberos La Salvadora 10 & Jirón de la Unión 1030 - Lima \\
\hline & 24 & Museo Municipal del Teatro & Jirón Huancavelica 240 - Lima \\
\hline & 25 & Museo Sanmartiniano & Jirón Bolognesi 467 - Lima \\
\hline & 26 & Museo del Señor de los Milagros & Jirón Huancavelica 583 - Lima \\
\hline \multirow{5}{*}{ Museos Religiosos } & 27 & Museo de Arte Religioso de la Catedral de Lima & Jirón Carabaya Cuadra $2 \mathrm{~s} / \mathrm{n}$ - Lima \\
\hline & 28 & Museo del Palacio Arzobispal de Lima & Jirón Carabaya Cuadra $2 \mathrm{~s} / \mathrm{n}$ - Lima \\
\hline & 29 & Museo de los Descalzos & $\begin{array}{l}\text { Calle Manco Capac } 202 \text { Alameda de los } \\
\text { Descalzos - Lima } \\
\end{array}$ \\
\hline & 30 & Museo del Convento de Santo Domingo & Jirón Camana 170 - Lima \\
\hline & 31 & $\begin{array}{l}\text { Museo y Catacumbas de Lima. Conjunto Monumental } \\
\text { San Francisco de Lima }\end{array}$ & Esquina Jirón Lampa con Jirón Ancash - Lima \\
\hline \multirow{3}{*}{ Museos de Sitios } & 32 & Museo del Parque de la Muralla & Jirón Amazonas Cuadra 1 - Lima \\
\hline & 33 & Museo de Sitio Bodega y Quadra & Jirón Ancash 213 - Lima \\
\hline & 34 & Museo de Sitio del Mirador del Cerra San Cristobal & Cerro San Cristobal (cima) - Rimac \\
\hline \multirow{3}{*}{$\begin{array}{l}\text { Museos } \\
\text { especializados }\end{array}$} & 35 & Casa de la Gastronomía Peruana & Jirón Conde de Superunda 170 - Lima \\
\hline & 36 & Casa de la Literatura Peruana & Jirón Ancash 207 - Lima \\
\hline & 37 & Museo Numismático del Perú & Jirón Junín 781 - Lima \\
\hline \multirow{2}{*}{ Casas Museo } & 38 & Casa Museo José Carlos Mariátegui & Jirón Washignton 1946 - Lima \\
\hline & 39 & Museo Naval - Casa Grau & Jirón Huancavelica 172 - Lima \\
\hline Museo Cementerio & 40 & Museo Cementerio PresbiteroMatias Maestro & Jirón Ancash 1611, Barrios Altos - Lima \\
\hline
\end{tabular}

Elaborada por Ana María Lebrún A. y Fabiola Castillo C. 


\section{METODOLOGÍA}

La investigación es de tipo cuantitativo - no experimental, con un enfoque descriptivo - transversal. La unidad de análisis son los museos; para ello, se han seleccionado seis museos y/o espacios de exposición, que

Tabla 3.

Relación de museos seleccionada para el diseño de la propuesta de recuperación del Patrimonio Cultural de la Humanidad del Centro Histórico de Lima.

\begin{tabular}{|c|c|c|c|c|}
\hline $\begin{array}{l}\text { NOMBRE DEL } \\
\text { MUSEO }\end{array}$ & ESTADO & DIRECCIÓN & $\begin{array}{l}\text { DECLARATORIA DE } \\
\text { PATRIMONIO } \\
\text { CULTURAL DE LA } \\
\text { NACIÓN }\end{array}$ & $\begin{array}{c}\text { FECHA DE } \\
\text { DECLARATORIA } \\
\text { DE } \\
\text { PATRIMONIO }\end{array}$ \\
\hline $\begin{array}{l}\text { Museo Andrés del } \\
\text { Castillo }^{3}\end{array}$ & Restaurado & $\begin{array}{l}\text { Jr. De La Unión } N^{\circ} 1030 \text { Cercado } \\
\text { de Lima }\end{array}$ & R.M. N 0928-1980-ED & $23 / 07 / 1980$ \\
\hline $\begin{array}{ll}\text { Museo } & \text { Nacional } \\
\text { Afroperuano }^{4} & \end{array}$ & Restaurado & $\begin{array}{l}\text { Jr. Áncash No } 542 \\
\text { Cercado de Lima }\end{array}$ & R.S. N ${ }^{\circ} 2900-1972-E D$ & $28 / 12 / 1972$ \\
\hline $\begin{array}{l}\text { Casa de la Literatura } \\
\text { Peruana }^{5}\end{array}$ & Remodelado & $\begin{array}{l}\text { Jr. Áncash N } 207 \\
\text { Cercado de Lima }\end{array}$ & R.S. $N^{\circ} 2900-1972-E D$ & $28 / 12 / 1972$ \\
\hline $\begin{array}{l}\text { Casa de la Gastronomía } \\
\text { Peruana }^{6}\end{array}$ & Remodelado & $\begin{array}{l}\text { Jr. Conde de Superunda } N^{\circ} 170- \\
\text { Cercado de Lima }\end{array}$ & R.S. $N^{\circ} 2900-1972-E D$ & $28 / 12 / 1972$ \\
\hline $\begin{array}{l}\text { Museo de Sitio Bodega y } \\
\text { Quadra }^{7}\end{array}$ & Restaurado & $\begin{array}{l}\text { Jr. Áncash N²09-213-217 Cercado } \\
\text { de Lima }\end{array}$ & $\begin{array}{l}\text { R.D.N. N } 1327-2004- \\
\text { INC }\end{array}$ & $03 / 12 / 2004$ \\
\hline Museo de Arte de Lima ${ }^{8}$ & Restaurado & $\begin{array}{l}\text { Paseo Colón } \mathrm{N}^{\circ} 125 \text { Cercado de } \\
\text { Lima }\end{array}$ & R.S. $N^{\circ}$ 2900-1972-ED & $28 / 12 / 1972$ \\
\hline
\end{tabular}

Elaboración propia han sido abiertos al público recientemente, luego de un proceso de remodelación y/o restauración de la infraestructura existente. Todos los museos se encuentran ubicados en el área declarada como Centro Histórico de Lima.

3 El Museo Andrés del Castillo se ubica en la casa Belén, monumento histórico de arquitectura republicana, siendo restaurado para convertirse en museo e inaugurado el 06 de noviembre de 2008. Este espacio cultural ha sido ejecutado en memoria de quien en vida fue un estudiante de Ingeniería de Minas, y sus padres lo realizaron en su memoria. Este museo alberga una importante colección de minerales, cerámica de la cultura Chancay y vestimenta del antiguo Perú, tales como mantos, unkus, calzado, fajas, cintas, pelucas, gorros, entre otros.

4 El Museo Nacional Afroperuano, ubicado en la Casa de las Trece Monedas, fue inaugurado el 04 de junio de 2009, en el Día de la Cultura Afroperuana y día del nacimiento de Nicomedes Santa Cruz, principal exponente decimista y del folclore afroperuano. La casona del siglo XVIII, de estilo rococó francés, fue restaurada para convertirse en un espacio cultural, abierto al público, donde se presenta el proceso de la migración africana, así como diversas piezas y objetos de la época colonial.

5 La Casa de la Literatura Peruana ocupa lo que en su momento fue la antigua Estación Central de Desamparados, desde el 20 de octubre de 2009, cuenta, de manera lúdica, la vida y obra de escritores peruanos representativos, a través de imágenes, videos, textos, audios y libros.

6 La Casa de la Gastronomía Peruana, inaugurada el 25 de marzo de 2011, albergó previamente en sus espacios al Museo Postal y Filatélico del Perú. Sus espacios presentan la historia de la gastronomía desde la época prehispánica hasta la actualidad, mediante textos, elementos tridimensionales, recreaciones, entre otros.

7 El Museo de Sitio Bodega y Quadra, ubicado en el Centro Histórico de Lima, fue inaugurado el 10 de noviembre de 2012. La casona que alberga el museo es una edificación de estilo republicano que se encontraba en estado ruinoso, siendo restaurada para ser convertida en un espacio cultural donde se presenta la historia de Lima, a través de objetos coloniales y republicanos recuperados durante el proceso de conservación y puesta en valor del inmueble.

8 El Museo de Arte de Lima, antes Palacio de la Exposición, construido en el siglo XIX, en el marco de la Exposición Internacional de Lima del año 1,872, ha sido recientemente restaurado, reabriendo sus salas de exposición permanente el 09 de setiembre de 2015 con más de 1200 piezas en exposición donde se exhiben piezas arqueológicas, textiles, pinturas, entre otras, haciendo un recorrido a través de la historia del arte peruano. 


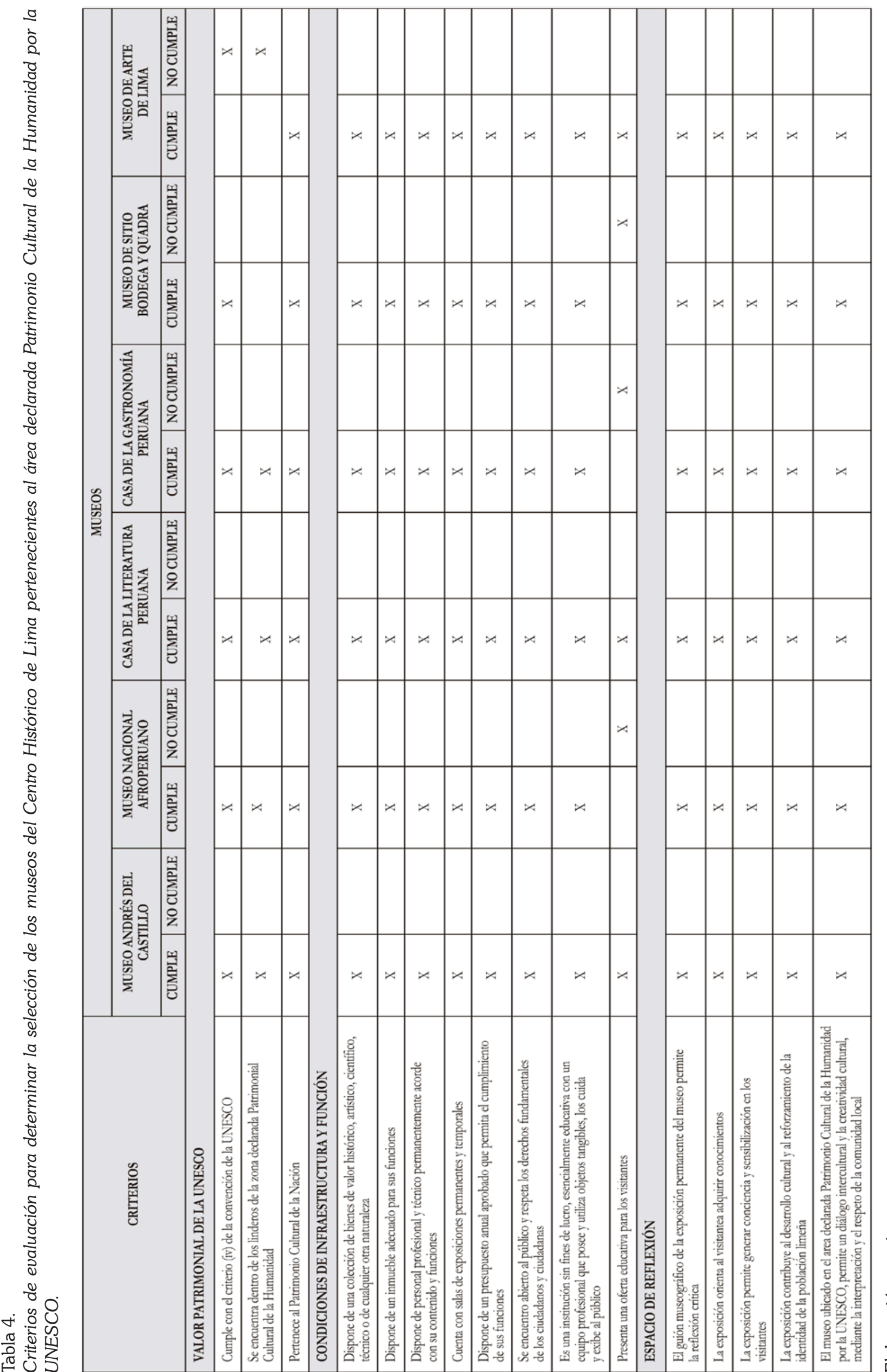




\section{RESULTADOS}

Los museos seleccionados para la presente investigación, que se encuentran ubicados dentro del área declarada como Centro Histórico de Lima cuentan con lo siguiente:

\section{Valor patrimonial de la UNESCO}

Los museos seleccionados, ubicados en el área declarada Patrimonio Cultural de la Humanidad, aportan un excelente testimonio del desarrollo arquitectónico y urbano de los centros coloniales españoles de gran importancia política, económica y cultural en América Latina. Asimismo, representa una expresión de proceso cultural que preserva valores arquitectónicos, tecnológicos, tipológicos, estéticos, históricos y urbanos para la humanidad.

El Museo de Arte de Lima es el único museo que no se encuentra dentro de los linderos del área declarada Patrimonio Cultural de la Humanidad (ver figura 1), pero sí pertenece al Centro Histórico de Lima. La decisión de considerarlo se debe a que es un museo de gran relevancia social y cultural.

Cada uno de los museos seleccionados han sido declarados Patrimonio Cultural de la Nación por el Instituto Nacional de Cultura (actual Ministerio de Cultura) y el Ministerio de Educación (ver tabla 3).

\section{Condiciones de infraestructura y función}

El $100 \%$ de museos cuenta con una colección que permite brindar información, conocimiento y reflexión a los visitantes en general. La totalidad de museos funcionan en espacios arquitectónicos habilitados para cumplir la función de museos, los mismos que han sido restaurados o remodelados.

Los museos cuentan con personal profesional y técnico para llevar a cabo sus actividades diarias y puedan estar abiertos al público en general, sin ningún tipo de restricciones ni limitaciones, respetando los derechos fundamentales de todos los ciudadanos.

Todas las instituciones museísticas seleccionadas son sin ánimo de lucro, benefician a los visitantes locales, regionales, nacionales e internacionales, cumpliendo sus funciones en beneficio de los niños, adolescentes, jóvenes, adultos y adultos mayores, a través de una oferta educativa para todo tipo de público. En el caso del Museo Nacional Afroperuano, Casa de la Gastronomía Peruana y el Museo de Sitio Bodega y Quadra, se encuentran en la etapa de estudio para la elaboración de una oferta educativa para los visitantes.

Teniendo en cuenta que una de las funciones principales de los museos es la exposición y/o exhibición, todos los museos seleccionados cuentan con exposiciones permanentes $y$ temporales, contando con áreas específicas para exposición, igualmente disponen de un presupuesto anual para el mantenimiento de sus instalaciones.

\section{Espacios de reflexión}

Los museos seleccionados, son espacios de educación continua y reflexión crítica, debido a que, mediante las exposiciones permanentes y temporales generan identidad, conciencia y empoderamiento de la población por el Centro Histórico de Lima y el Patrimonio Cultural de la Humanidad, el espacio público y el suelo urbano.

Los museos, al ser parte de la comunidad en general, contribuyen a la conservación de su pasado y de su individualidad $y$, al mismo tiempo, descubren, estudian, preservan, defienden y exaltan sus valores humanos $y$ universales para integrarlos a la sociedad.

Las exposiciones logran generar conciencia y sensibilización en los visitantes a través de un acercamiento a la comunidad, debido a que es el canal conductor para reforzar o apoyar los conocimientos adquiridos en clase. Asimismo, con las diversas actividades se genera una reflexión crítica que contribuye al desarrollo cultural, preservando y conservando el Patrimonio Cultural de la Nación para las generaciones futuras, permitiendo el diálogo intercultural y la creatividad cultural, mediante la interpretación y el respeto de la comunidad local. 


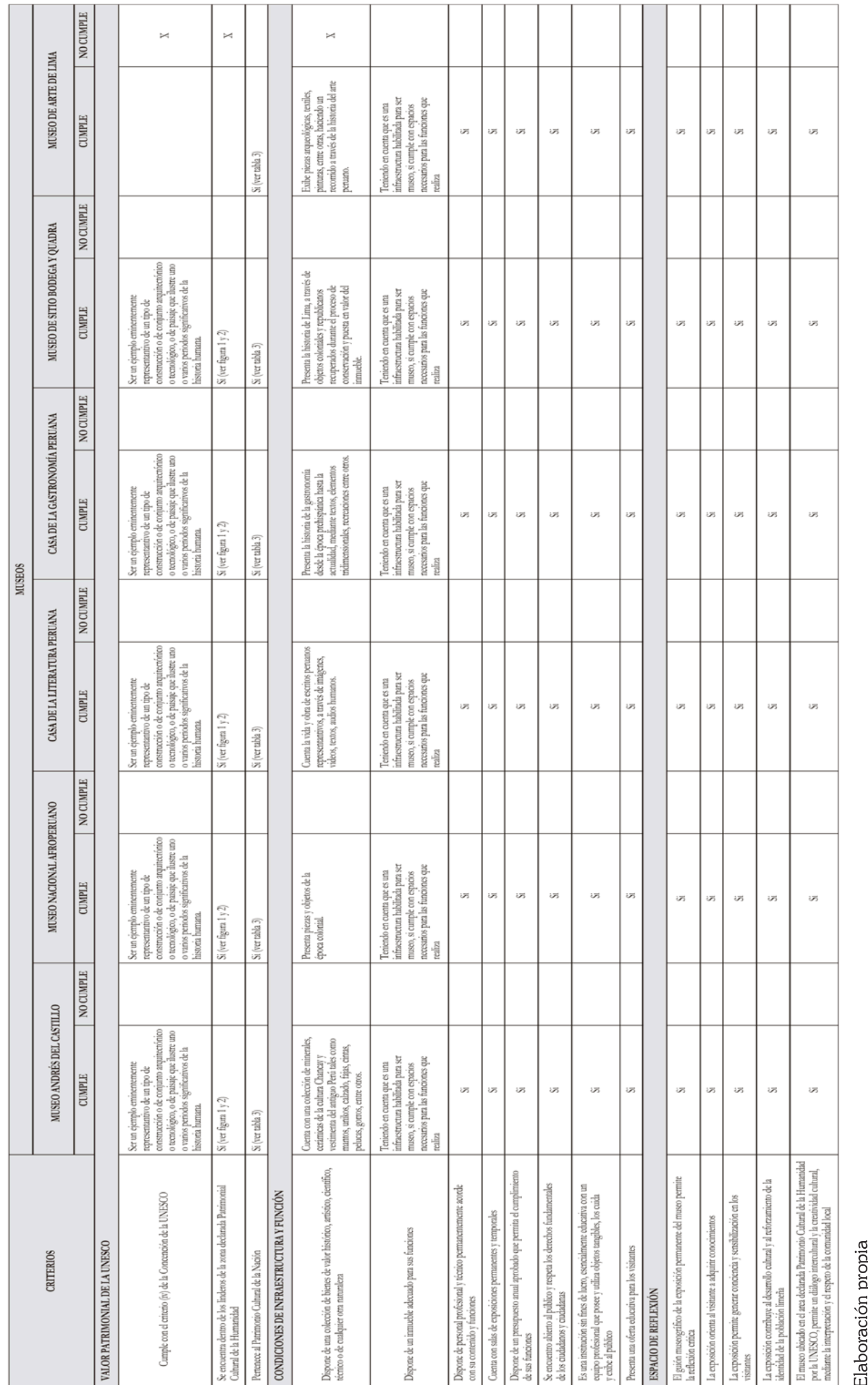




\section{CONCLUSIONES}

Los museos ubicados dentro del área declarada Patrimonio Cultural de la Humanidad por la UNESCO, al ser espacios de reflexión, presentan distintos temas del conocimiento para que a los habitantes y visitantes nacionales y extranjeros les genere conciencia y sensibilicen sus emociones y sentidos.

Considerando que, en la actualidad, las exposiciones permanentes y temporales contribuyen al desarrollo cultural $y$ al reforzamiento de la identidad de la población en general, estos espacios de reflexión pueden presentar la problemática que vive el Centro Histórico de Lima, a través de exposiciones temporales, para que los habitantes y visitantes nacionales y extranjeros se concienticen y sensibilicen para lograr la recuperación del Patrimonio Cultural de la Nación, el espacio público y el suelo urbano.

Al generar conciencia y sensibilización en la comunidad en general, la realidad actual del Centro Histórico de Lima cambiaría, planteando, de esta manera, políticas públicas y culturales pertinentes para la recuperación del espacio, en todas sus dimensiones, considerando al Centro Histórico de Lima como corazón sociocultural de Lima y, empoderarse, de esta manera, del espacio público, permitiendo que la ciudad mejore, mediante una propuesta de desarrollo integral, inclusivo y equitativo.

Con las exposiciones temporales, se lograría detener el proceso de deterioro del Patrimonio Cultural de la Nación, el espacio público y el suelo urbano del Centro Histórico de Lima $y$, de esta manera, se logren conservar $y$ restaurar las edificaciones patrimoniales que forman parte de la memoria e imagen urbana, ya que sin ese valor se perdería la singularidad $e$ identidad del lugar. Se debe mencionar que la importancia de conservar y restaurar radica no solo en rescatar el legado arquitectónico declarado como patrimonio, sino también se trata del rescate de escenarios que nos permiten viajar en el tiempo, recreando y viviendo la historia.

Los museos, como en todo el mundo, representan uno de los eslabones esenciales para la sostenibilidad de los centros históricos como espacios para que sean visitados, contribuyendo al desarrollo cultural y al reforzamiento de la identidad de la población limeña. Los museos ubicados en la zona monumental de Lima permiten el diálogo intercultural y la creatividad cultural, introducen procesos cognitivos y emocionales a los visitantes, mediante la interpretación y el respeto de la comunidad local. 


\section{REFERENCIAS}

Centro de Investigación, Documentación y Asesoría Poblacional - CIDAP (s.f.). Cifras de tugurización en viviendas en Lima Metropolitana. Recuperado de https://es.scribd.com/document/15024059/ Cifras-de-TugurizacionenViviendas-en-Lima-Metropolitana

Consejo Internacional de Museos, ICOM. (2007). $22^{\text {a }}$ Asamblea General Viena (Austria). Recuperado de https://icom.museum/wp-content/uploads/2018/07/ICOMs-Resolutions_2007_Esp.pdf

Consejo Internacional de Museos, ICOM. (2017). Estatutos. Recuperado de https://icom.museum/ wp-content/uploads/2018/07/2017_ICOM_Statutes_SP_01.pdf

Consejo Internacional de Museos, ICOM. (s.f.). Estatutos del ICOM. Recuperado de http://icom. museum/fileadmin/user_upload/pdf/Statuts/2016_Statutes_ES.pdf

Consejo Internacional de Monumentos y Sitios Históricos, ICOMOS. (1964). Carta Internacional para la Conservación y Restauración de los Monumentos y los Sitios Históricos (Carta de Venecia). Recuperado de http://www.icomos.org/charters/venice_sp.pdf

Consejo Internacional de Monumentos y Sitios Históricos, ICOMOS. (1987). Carta Internacional para la Conservación de Ciudades Históricas y Áreas Urbanas Históricas (Carta de Washington). Recuperado de http://www.icomos.org/charters/towns_sp.pdf

González, M., Gil, D. y Vilches, A. (2002). Los museos de ciencias como instrumentos de reflexión sobre los problemas del planeta. Recuperado de https:/www.uv.es/vilches/documentos\%20 enlazados/TEAMU\%20.pdf

Günther, J. (2012). Memorias de Lima. De haciendas a pueblos y distritos. Lima, Perú. Círculo Polar S.A.C.

Municipalidad Metropolitana de Lima (1999). Artículo 25. Ordenanza $\mathrm{N}^{\circ}$ 201. Plan Maestro Centro de Lima. Recuperado de http:/www.cultura.gob.pe/sites/default/files/paginternas/tablaarchivos/04/ ordenanza-n-201.pdf

Municipalidad Metropolitana de Lima. (2014). Plan Maestro del Centro Histórico de Lima al 2025 Recuperado de http://www.munlima.gob.pe/images/descargas/programas/prolima/PLANMAESTRO.pdf

Organización de las Naciones Unidas para la Educación, la Ciencia y la Cultura, UNESCO. (1976). Declaración de Nairobi. Recomendación relativa a la Salvaguardia de los Conjuntos Históricos y su función en la vida contemporánea. Recuperado de http://www.programapd.pe/ limapatrimoniomundial/documentos/declaracion_de_nairobi.pdf

United Nations Educational, Scientific and Cultural Organization, Intergovernmental Committee for the Protection of the World Cultural and Natural Heritage, World Heritage Centre (2015). Operational Guidelines for the Implementation of the World Heritage Convention. Recuperado de http://whc. unesco.org/en/guidelines

Fecha de aceptación: 21-11-18.

Fecha de recepción: 05-11-18. 